\title{
RESPONSE AND DAMAGE EVOLUTION OF SINGLE EDGE NOTCHED TIMBER BEAMS UNDER THREE-POINT BENDING
}

\author{
Eliška Šmídová*, Petr Kabele, Michal ŠEjnoha \\ Czech Technical University in Prague, Faculty of Civil Engineering, Department of Mechanics, Thákurova 7, \\ 16629 Prague 6, Czech Republic \\ * corresponding author: eliska.smidova@fsv.cvut.cz
}

AbStract. Two groups of small-size single edge notched beams (SENB) made of European spruce (Picea abies) were tested in three-point bending (3PB) until failure under displacement control. The first group comprised of eight solid and two glued laminated (GL) timber beams manufactured with (a) the single edge notch at the bottom of the mid-span and (b) the reduced ligament depth. The second group consisted of four GL timber beams with the single edge notch only. We employed digital image correlation (DIC) to quantify strains and displacements, capture the damage evolution, and track the sequence of failure patterns. In this work, we present response of the beams in terms of load vs. crosshead displacement of the moving crosshead and load vs. crack tip opening displacement (CTOD).

KEYwORDS: Three-point bending (3PB), single edge notched beams (SENB), reduced ligament depth, timber, crack tip opening displacement (CTOD).

\section{INTRODUCTION}

An experimental campaign has been carried out at Czech Technical University in Prague to determine both the response and the damage evolution of single edge notched beams (SENB) with fibers along the beam length. We loaded two groups of beams made of European spruce in three-point bending (3PB). The first group beams were sawn with the notch and an additionally reduced ligament depth to induce the fibers rupture (splinter) under tension stress parallel with the grain at or close to the ligament. Compared to it, the second group was cut with the notch only to initiate cracking along the grains at the notch tip exposed to tension perpendicular to the grain.

RILEM and CIB-W18 (11) recommend performing the 3PB test of SENB (Figure 1) to obtain a stable crack extension in the direction parallel with the grain from an initial notch to the complete separation of the crack faces. Representing the fracture mode I, i.e. cracking under tension stress perpendicular to the crack plane, the test is used for calculation of fracture energy. Many studies involving the SENB bending test have been conducted ([2], [3], [4], [5], [6], [7]).

Out of timber structure failure cases where a crack could be detected, the most frequent failure type is cracking in the grain direction corresponding to $75 \%$ while shear, tension and other failures represent $8 \%$, $6 \%$ and $11 \%$ of the cases, respectively $(8)$. General failure modes of timber beams are depicted in Figure 2- Figure 4([9). In the midspan zone (Figure 2), the tension stress leads to fibers rupture that we can categorize as a brittle failure. Longitudinal compression causes ductile failure in the form of kink bands. Thus, load-bearing capacity of a beam in bending is usually limited by the brittle behavior of timber in the tension zone and can be more reduced with the presence of natural defects. Nevertheless, shear stress can be governing for the design of some timber members, e.g. short beams. Its maximum is reached around the supports causing brittle failure parallel with the grain where the fibers bundles or layers slide (Figure 3). The area of a support or a loading point is typical for compression stress perpendicular to the fibers that leads to a ductile failure (Figure 4).

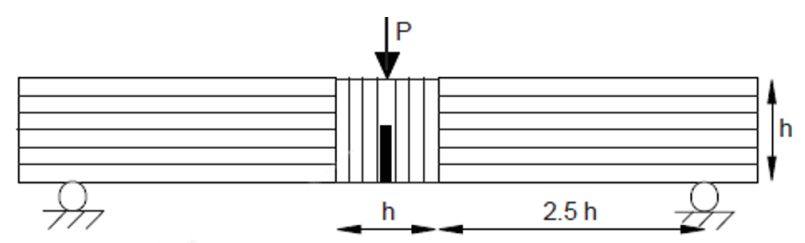

Figure 1. Single edge notched beam [1].

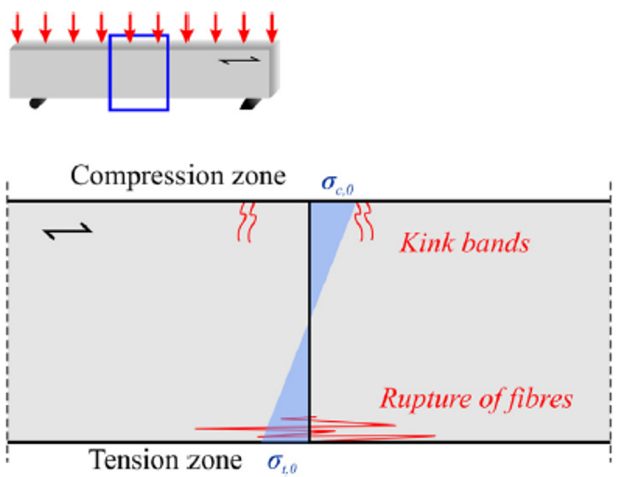

Figure 2. Sketch for bending failure 9]. 


\begin{tabular}{cccccccc}
\hline Group & $\begin{array}{c}l \times h \times w \\
{[\mathbf{c m}]}\end{array}$ & $\begin{array}{c}l_{n} \\
{[\mathbf{c m}]}\end{array}$ & $\begin{array}{c}w_{l i} \\
{[\mathbf{c m}]}\end{array}$ & Material & $\begin{array}{c}\text { Count } \\
{[-]}\end{array}$ & Failure & Specimens \\
\hline & & & & Solid & 5 & F1 & $\# 01-\# 05$ \\
1 & $40 \times 10 \times 5$ & 1 & 2 & Solid & 3 & F2 & $\# 06-\# 08$ \\
& & & & GL & 2 & F2 & $\# 09-\# 10$ \\
2 & $40 \times 10 \times 4$ & 1 & - & GL & 4 & F3 & $\# 11-\# 14$ \\
\hline
\end{tabular}

TABLE 1. Test program characteristics and first failures types (F1 - splinter around the ligament, F2 - splinter around the ligament + shear, F3 - parallel with the grain).

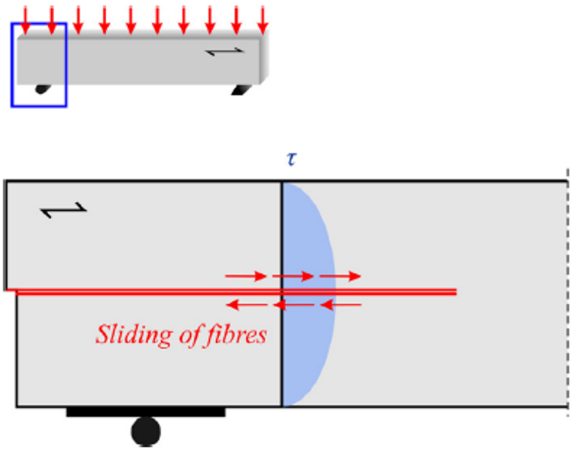

Figure 3. Sketch for shear failure 9 .
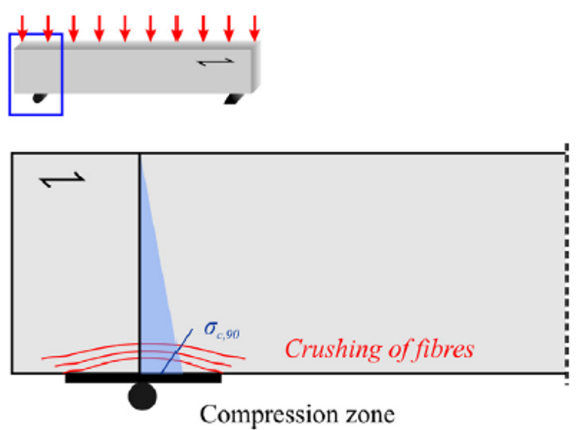

FiguRE 4. Sketch for compression failure [9].

\section{TEST PROCEDURE AND MATERIAL}

We conducted three-point bending test (3PBT) of two groups of beams, both with the length $l$ of $40 \mathrm{~cm}$, cross-section height $h$ of $10 \mathrm{~cm}$ and single edge notch with the length $l_{n}$ of $1 \mathrm{~cm}$ (Figure 5) and the width $w_{n}$ of $0.1 \mathrm{~cm}$. The first group was composed of eight solid and two glued laminated timber beams with crosssection width $w$ of $5 \mathrm{~cm}$ and reduced ligament width $w_{l i}$ of $2 \mathrm{~cm}$. The second group consisted of four glued laminated timber beams with cross-section width $w$ of $4 \mathrm{~cm}$.

We ran the experiment under displacement control at the rate of $2 \mathrm{~mm} / \mathrm{min}$. In this regime, we were able to record the descending branch of the load-displacement curve. Furthermore, digital image correlation (DIC) was applied, with mostly $10 \mathrm{sec}$ time interval, to capture strains, displacements (e.g., crack tip opening displacement CTOD, see Figure 5), damage evolution and failure type sequence.

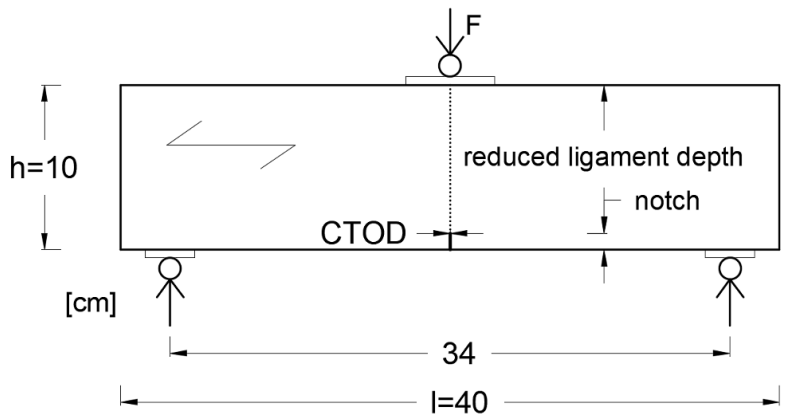

FIgURE 5. Three-point bending test (3PBT) configuration common for all the beams: length of $40 \mathrm{~cm}$, cross-section height of $10 \mathrm{~cm}$ and single edge notch length $l_{n}$ of $1 \mathrm{~cm}$.

\section{Results And Discussion}

The following section describes damage evolution and response of the beams. Overview of this experimental campaign is given in Table 1 for observed first failure types. Let us note that the failure of fibers crushing due to compression stress perpendicular to the grain around the loading plate and supports is present in every beam influencing the response.

\subsection{Group one: NOTCHED BEAMS WITH REDUCED LIGAMENT DEPTH}

The load-crosshead displacement responses of the group one beams with the single edge notch and reduced ligament depth are plotted in Figure 6 and Figure 7 for the first failures denoted F1 - splinter around or at the ligament and F2 - splinter around or at the ligament accompanied by shear failure, respectively. Furthermore, for the beams with F1, the load-CTOD curves are shown in Figure 8 The following subsections present the damage evolution and failure type sequence of individual beams.

\subsection{1. ВЕАM \#01}

The beam \#01 represents the failure type F1 for the beams \#01 - \#05. Its damage evolution is shown in Figure 9. Observing the photos of the load stages, we can see failure F1 - splinter at or in the vicinity of the reduced ligament being the only failure type that occurred. 


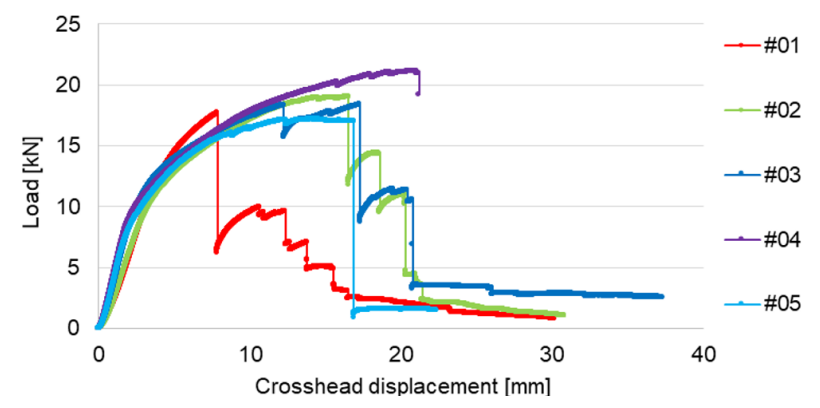

Figure 6. Load vs. crosshead displacement of the group one beams with the first failure F1 - splinter around the ligament.

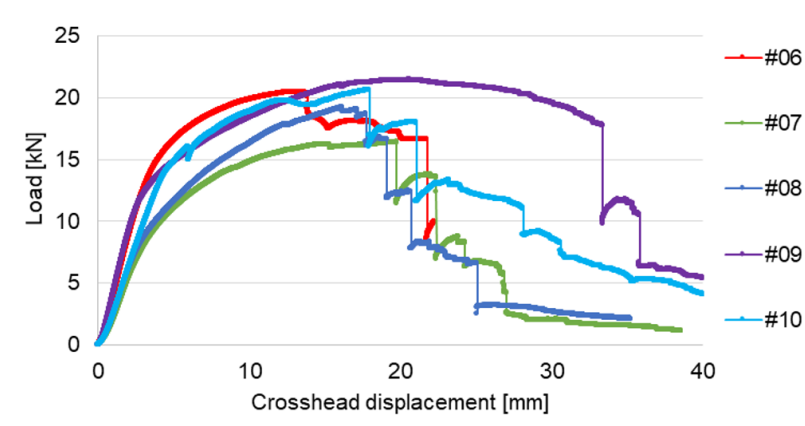

Figure 7. Load vs. crosshead displacement of the group one beams with the first failures F2 - splinter around the ligament + shear.

\subsubsection{BEAM \#08}

The beam \#08 represents a specific type of the failure F2 occurring in two beams $(\# 08, \# 10)$ out of the group one. The damage evolution is shown in Figure 10. The photos of the load stages show that failure F2 is composed of (a) splinter at or in the vicinity of the reduced ligament and (b) shear failure of a grain bundle reaching at the beam length and occurring both inside and at the cross-section boundaries, namely at the painted front face of the beam, see Figure 11 (left). The latter failure causes leaning of the sheared grains against the other ligament face affecting the overall response, especially CTOD of the notch.

\subsubsection{BЕAM \#09}

The beam \#09 represents the failure type F2 occurring in three beams (\#06, \#07, \#09) out of the group one. The damage evolution is shown in Figure 12 Observing the photos of the load stages, we can see that failure F2 covers (a) splinter at or in the vicinity of the reduced ligament and (b) shear failure of a grain bundle inside the cross-section, see Figure 11 (right).

\subsection{Group TWO: NOTCHED BEAMS}

The load-crosshead displacement responses of the group two beams with the single edge notch only are plotted in Figure 13 for the failure denoted here F3 - parallel with the grain being initiated at the

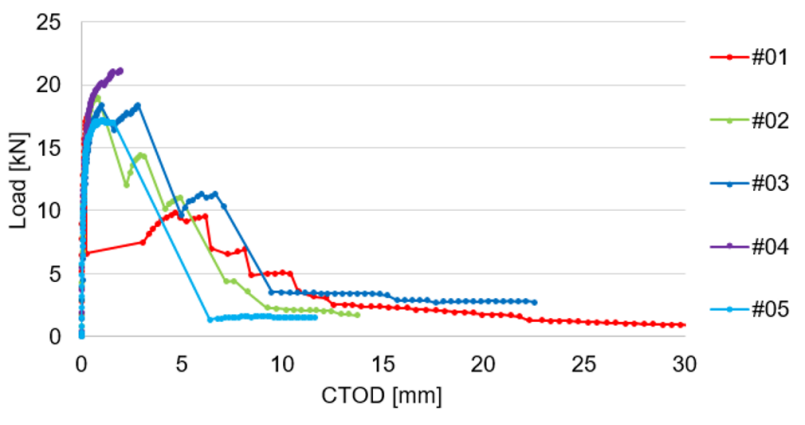

FiguRE 8. Load vs. crack tip opening displacement (CTOD) with the first failure F1.
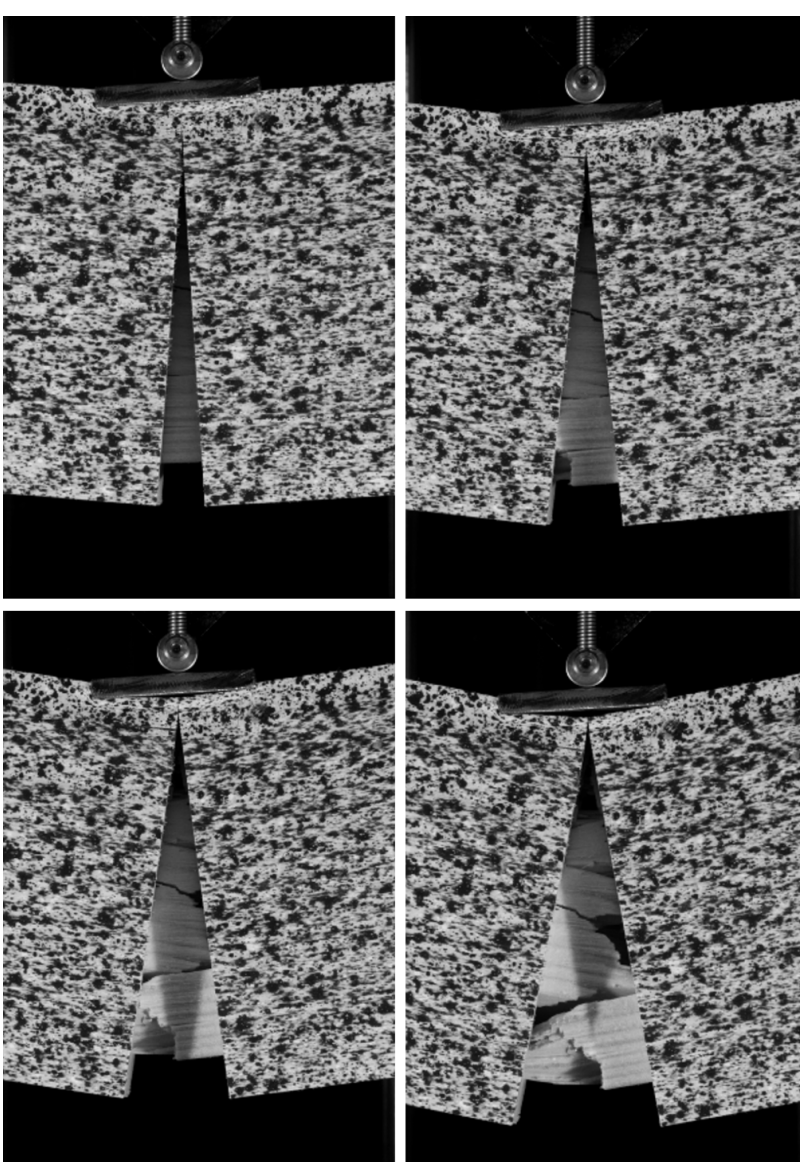

Figure 9. Damage evolution of the beam \#01 with the first failure F1 - splinter around the ligament.

notch tip. Let us mention that we do not report on the fifth beam from group two due to the presence of cross grain although the first failure type was also F3 - along the grain. We present the response of the beam \#13 only up to the first crack initiation (F3) that was consequently accompanied by unequal vertical displacement along the cross-section width above one of its supports resulting in torsion of the beam. Compared to it, the beam \#12 response captures not only the first crack initiation (F3) but also its opening. The following subsections present damage evolution and failure type sequence of individual beams \#11 

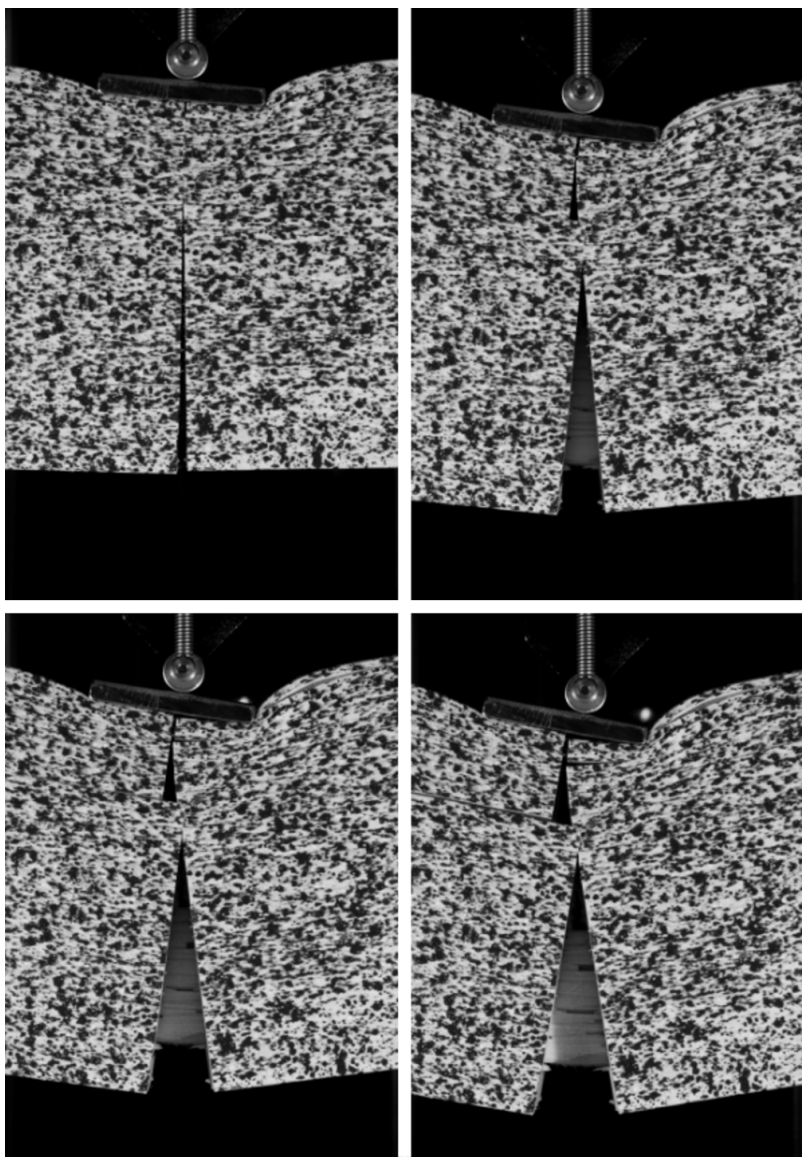

Figure 10. Damage evolution of the beam \#08 with the failure F2 - splinter around the ligament and shear failure.
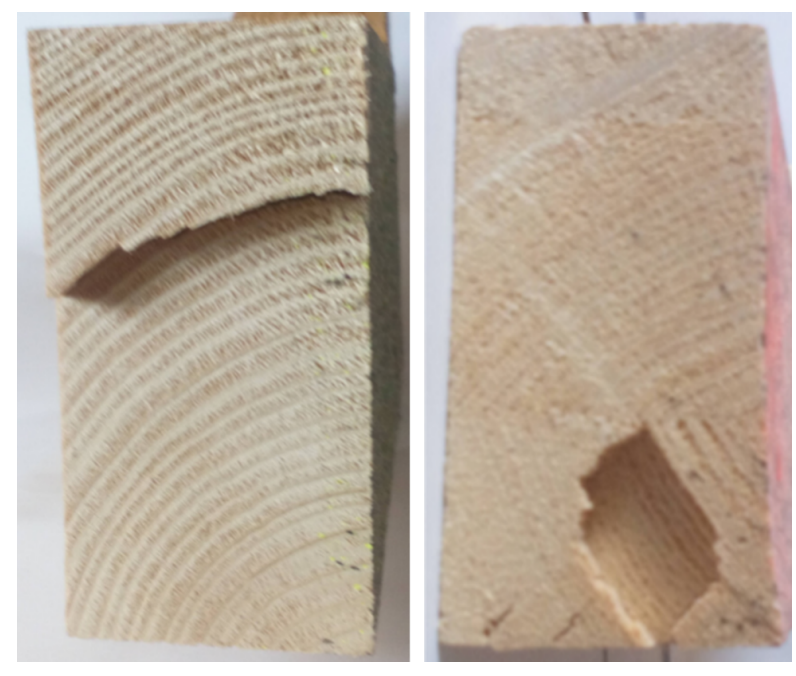

Figure 11. The end of the beam \#08 (left) and \#09 (right) demonstrating the shear failure.

and \#14.

\subsubsection{BEAM \#11}

The beam \#11 failed in tension. We can see in Figure 14 that (a) the first crack was initiated at the
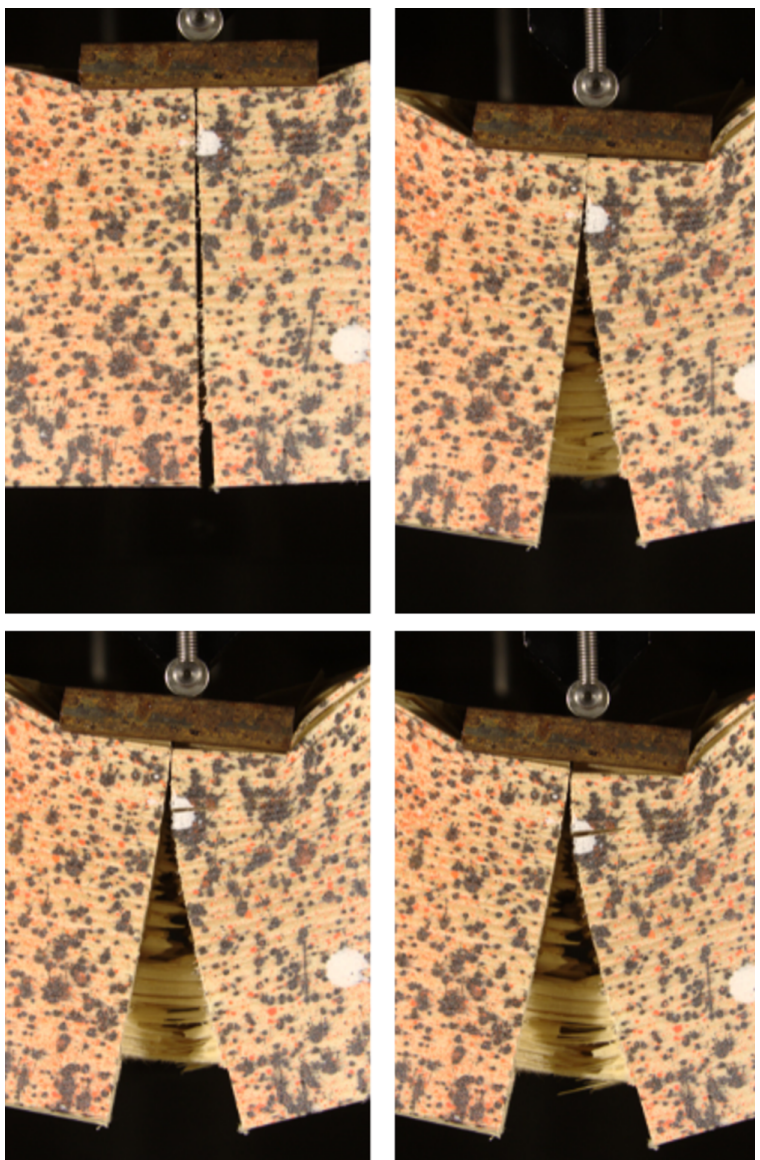

Figure 12. Damage evolution of the beam \#09 with the failure F2 - splinter around the ligament and shear failure.

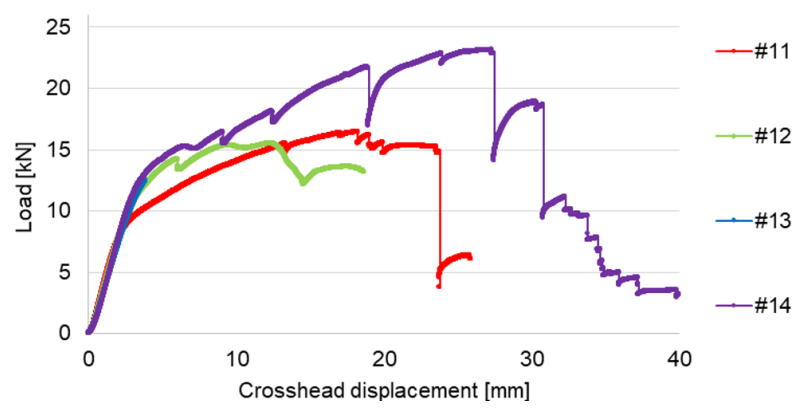

FigURE 13. Load vs. crosshead displacement of the group two beams with the first failure F3 - parallel with the grain.

notch tip and spread along the grain (F3) and then (b) splinter above the notch occurred. The similar crack pattern can be visible on the back face of the beam, see Figure 15]

\subsubsection{BЕАM \#14}

The failure pattern of the beam \#14 is the same as that of the beam \#11 except that the splinter above the notch is accompanied by shear failure of a timber layer in the middle of the beam height reaching the end of the beam Figure 16. The overall crack pattern 

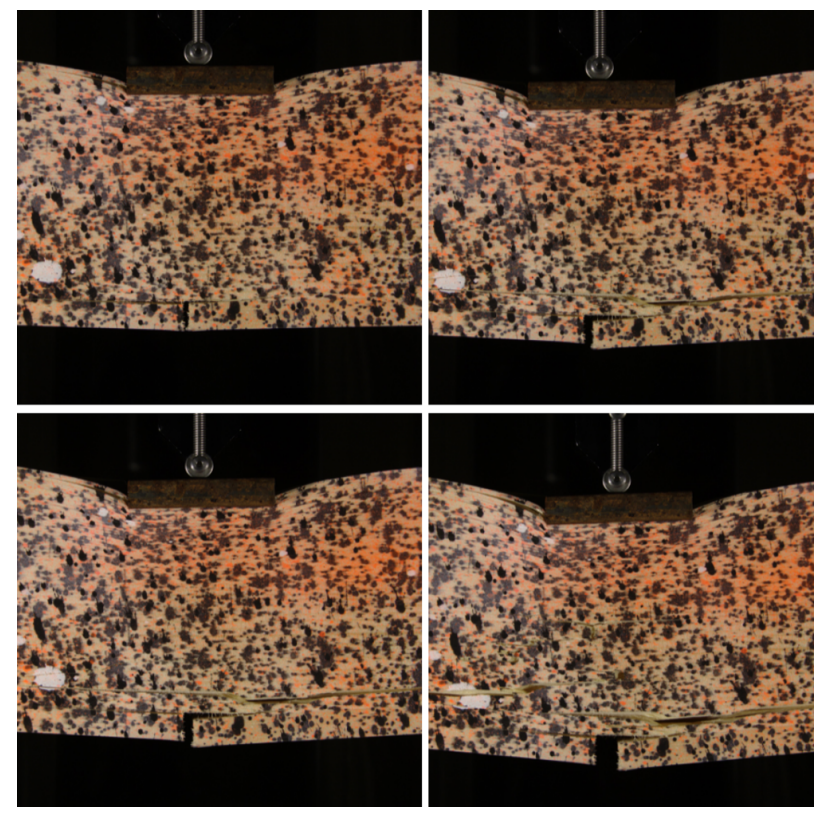

Figure 14. Damage evolution of the beam \#11 with the failure F3 - parallel with the grain followed by splinter above the notch.

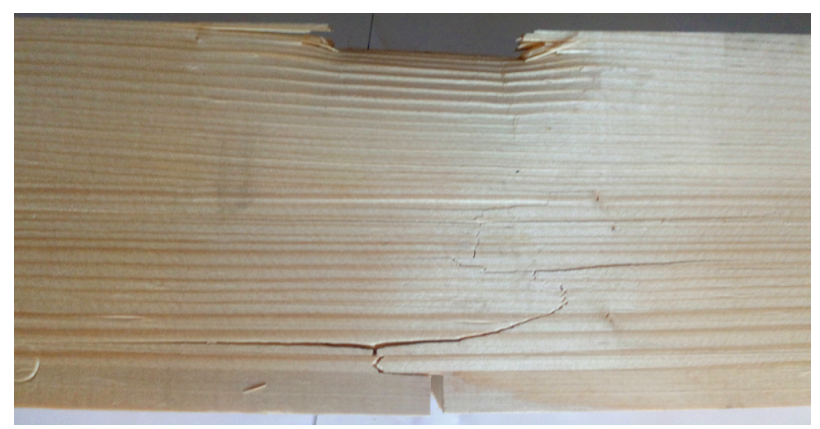

Figure 15. Back face of the beam \#11.

on the back face is shown in Figure 17

\section{Conclusion}

We conducted experiments of single edge notched beams made of European spruce loaded in threepoint bending under displacement control employing a high-speed digital camera for digital image correlation (DIC). Ten beams (group one), with dimensions $l \times h \times w$ of $(40 \times 10 \times 5) \mathrm{cm}$, were manufactured with both the single edge notch of the height of $1 \mathrm{~cm}$ and the reduced ligament depth. The other four beams (group two), with dimensions $l \times h \times w$ of $(40 \times 10 \times 4) \mathrm{cm}$ were cut only with the notch.

Crushing of fibers under compression stress perpendicular to the grain occurred in all beams around the supports and the loading point. We observed the first failure of fibers rupture (splinter) under tension stress parallel with the grain in five beams of the group one. In the other five specimens of this group, the splinter was accompanied by shear failure in the form of sliding
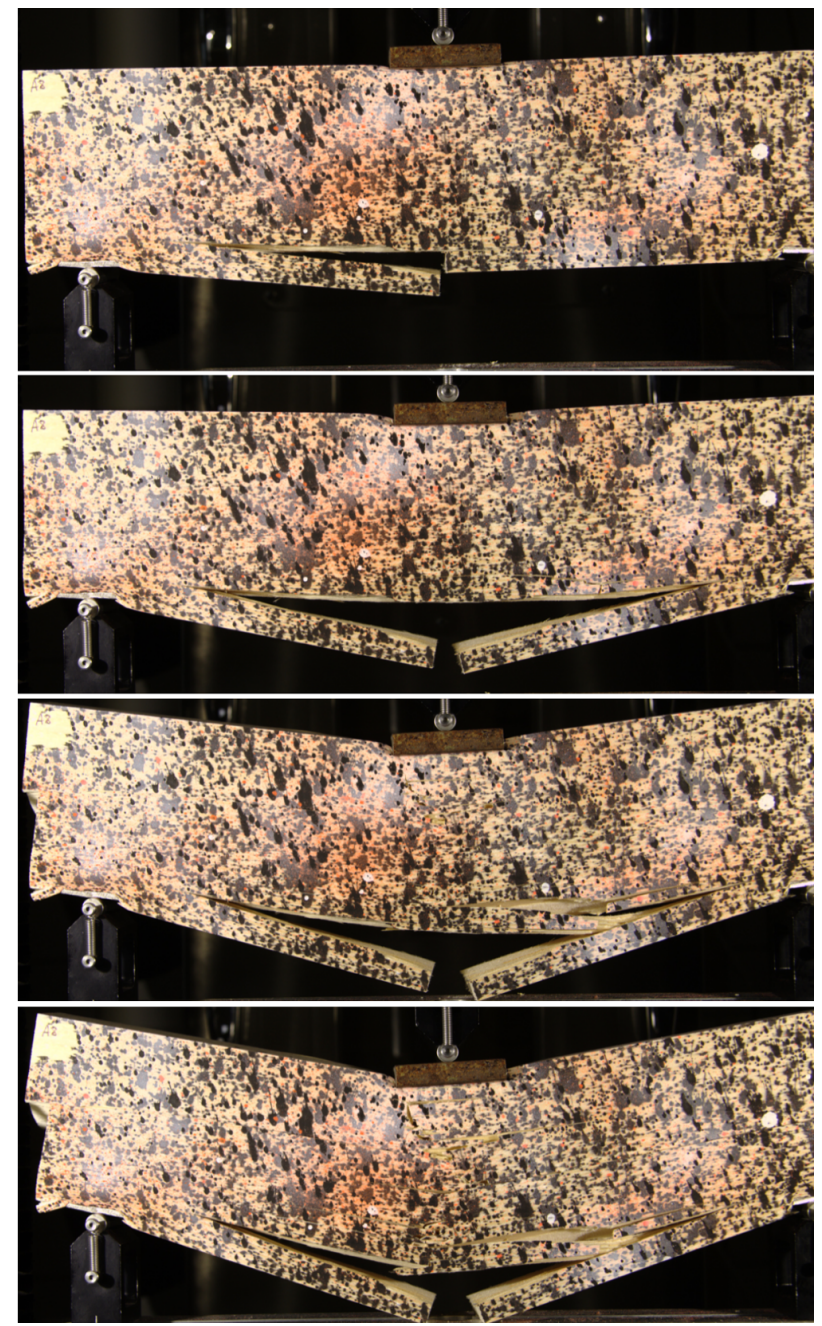

Figure 16. Damage evolution of the beam \#14 with failure F3 - parallel with the grain followed by splinter above the notch and shear failure.

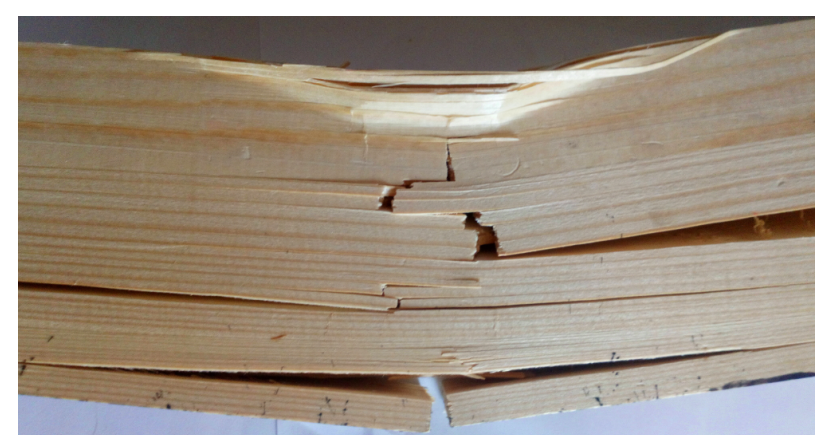

Figure 17. Back face of the beam \#14.

of fibers reaching the end of the beam. Regarding the failure of the group two, the first crack parallel with the grain was initiated at the crack tip on one or both sides followed by the second failure of the splinter above the notch that was in some cases accompanied by sliding of the fibers up to the beam end.

We captured the load-crosshead displacement response for all beams, mostly with the descending 
branch. Furthermore, we obtained the load-crack tip opening displacement (CTOD) for the beams with the reduced ligament depth (group one) where the first failure of splinter occurred.

\section{LIST OF SYMBOLS}

$h$ Cross-section height $[\mathrm{cm}]$

$l \quad$ Beam length $[\mathrm{cm}]$

$l_{n} \quad$ Vertical notch length $[\mathrm{cm}]$

$w$ Cross-section width $[\mathrm{cm}]$

$w_{l} i$ Ligament depth $[\mathrm{cm}]$

$w_{n}$ Vertical notch width $[\mathrm{cm}]$

\section{ACKNOWLEDGEMENTS}

The support by the GAČR grant No. 18-05791S is gratefully acknowledged.

\section{REFERENCES}

[1] Design of end-notched beams, 1989.

[2] M. Ashby, K. Eastering, R. Harrysson. The fracture and toughness of woods. In Proc $R$ Soc Lond A, vol. 398, pp. 261-280. 1985.

[3] L. Le-Ngoc, H. McCallion. On the fracture toughness of orthotropic materials. Eng Fract Mech 58:355-362, 1997.
[4] K. Ando, M. Ohta. Variability of fracture toughness by the crack tip position of coniferous wood 45:275-283, 1999.

[5] K. Watanabe, S. Shida, M. Ohta. Evaluation of endcheck propagation based on mode I fracture toughness of sugi (Cryptomeria japonica) 57:371-376, 2011.

[6] T. Nakao, C. M. E. Susanti, H. Yoshihara. Examination of the failure behavior of wood with a short crack in the radial-longitudinal system by singleedge-notched bending test. Journal of Wood Science 58(5):453-458, 2012. DOI:10.1007/s10086-012-1266-6.

[7] B. Franke, P. Quenneville. Analysis of the fracture behavior of Radiata Pine timber and Laminated Veneer Lumber. Engineering Fracture Mechanics 116:1-12, 2014. DOI:10.1016/j.engfracmech.2013.12.004

[8] M. Frese, H. J. Blaß. Failure analysis on timber structures in Germany p. 9, 2011.

[9] S. Franke, B. Franke, A. M. Harte. Failure modes and reinforcement techniques for timber beams - State of the art. Construction and Building Materials 97:2-13, 2015. DOI:10.1016/j.conbuildmat.2015.06.021 